\title{
Dos Zagros ao Eufrates: os Cassitas
}

\author{
From Zagros to Euphrates: the Kassites
}

\begin{abstract}
Priscila Scoville ${ }^{1}$
1 Doutoranda em História na UFRGS, sob orientação da Profá. Dra. Katia M. P. Pozzer. Estuda o sistema diplomático amarniano, com foco nos reinos independentes. Membro do LEAO (Laboratório de Estudos da Antiguidade Oriental) e representante do ASE (Association of Students of Egyptology). E-mail: pcnlscoville@gmail.com.
\end{abstract}

Recebido em 29 de julho de 2020; Aceito em 24 de janeiro de 2021.

DOI: $10.12957 /$ nearco.2020.56963

\section{Resumo:}

Este estudo visa elencar questões sobre o impacto cassita na Babilônia, pensando em elementos políticos e culturais. Assim, procuro trazer a trajetória do período da Babilônia Cassita, apontando os eventos e reis de destaque em seu contexto, traçando motivações e consequências, na medida do possível. Para tanto, realizo uma revisão historiográfica que elenca hipóteses para o preenchimento da fragmentação documental com as informações trazidas pela historiografia.

Palavras-chave: Babilônia; Cassitas; História Antiga.

\section{Abstract}

This paper aims to bring elements of the Kassite Babylonia in terms of political and cultural impact. Thus, it recreates the trajectory of Middle Babylonian Period, while focusing on events and kings, and thinking about motivations and consequences, when possible. For doing that, I made a historiographical review that points hypothesis to complete the documental fragmentation with academic information.

Keywords: Babylonia; Kassite; Ancient History.

A antiguidade próximo-oriental está repleta de grupos étnicos compondo um verdadeiro caldeirão cultural que, de tempos em tempos, vê alguma força emergir como dominante. Desde o terceiro milênio AEC, a Mesopotâmia e a Síria interagiam com um esquema de alianças que funcionava como instrumento de defesa e de conquista de 
bens econômicos. Com o tempo, as alianças foram ganhando outro formato, mais do que ganhos comerciais, elas passaram a visar uma manutenção de hegemonias, garantindo o status quo. Os tratados deixaram de ser uma alternativa à guerra para se tornarem ferramentas de construção de impérios (COHEN, WESTBROOK, 2002, p. 11). Nesse momento vemos nascer o Império de Hammurabi (c. 1792 - 1750 AEC), que unificou a Mesopotâmia em uma proporção não vista desde os tempos de Sargão da Acádia, quase 500 anos antes. Hammurabi, porém, não era sumério ou acadiano, mas amorita. Os amoritas eram um grupo semítico que se estabeleceu na Mesopotâmia em c. 2000 AEC, tendo entrado em conflito com diversas cidades até conquistarem a Babilônia (BIENKOWSKI, MILLARD, 2000, p. 16). Foi sob o domínio de desse povo estrangeiro que a Babilônia vivenciou um período chamado de Paleobabilônico (c. 2000 $-1595 \mathrm{AEC})$.

A interação cultural entre diferentes grupos não era um problema naquela realidade - muitos povos estavam presentes na Mesopotâmia, dividindo o espaço e se incorporando nas cidades. Por isso, não é uma surpresa pensar que os amoritas não foram os únicos a governar a Babilônia e estabelecer um reino forte e estável. O sucesso do Império de Hammurabi não foi muito longínquo e, pouco após sua criação, os governantes amoritas foram perdendo sua força. O Império Paleobabilônico não durou por muitas gerações após a morte de seu fundador. Na verdade, o imediato sucessor de Hammurabi, Samsuiluma I, já começou a enfrentar problemas. Era o início do colapso. Novas forças se formavam no Oriente Próximo, ameaçando as estruturas estabelecidas. Pouco a pouco, as cidades do sul foram perdendo a influência babilônica e a população começou a se ruralizar. É uma situação dramática, já que, durante séculos, o sul havia sido o centro religioso e cultural da Mesopotâmia (PODANY, 2010, pp. 119 - 120). Diversos reis locais iniciaram disputas contra a autoridade babilônica, criando um cenário propício para rebeliões. Mais do que isso, toda a Mesopotâmia passava por uma crise: muitos reinos entraram em declínio e cidades foram destruídas ou abandonadas. É um período curto e pouco documentado, sendo apelidado de "Idade das Trevas". 
ISSN 1982-8713

Sabemos, porém, que nesse contexto de confusão, a Babilônia caiu pelas mãos dos hititas; e os cassitas chegaram na Mesopotâmia - não demorou muito para conseguirem conquistar Babilônia, como veremos adiante. Os cassitas foram capazes de reestruturar o reino e o comandar pelos próximos 300 anos. A Mesopotâmia que emergiu da Idade das Trevas era completamente nova, com a ascensão política dos cassitas no sul e dos hurritas no norte (VAN DE MIEROOP, 2007, pp. 122 - 124).

A Babilônia Cassita é amplamente conhecida pela sua estabilidade, em especial, em relação aos contatos exteriores, apesar do imaginário comum ressaltar o período de Hammurabi ou o Período Neobabilônico - ofuscando, portanto, esse momento de tranquilidade. Os cassitas compõem a mais duradoura dinastia a governar o Reino da Babilônia, mas pouco se fala sobre eles. Sua origem tribal ainda é obscura, por isso, este trabalho busca jogar luz aos modos internos do período cassita para elencar algumas de suas características e, talvez, tornar sua história um pouco mais palpável.

\section{Os cassitas}

Os cassitas são um grupo tribal que se referia a si como galzu, um termo emprestado para o acadiano como kasshu. Eles, provavelmente, entraram na Mesopotâmia por meio dos montes Zagros, talvez vindos do Irã pela região norte do rio Diyala, (BIENTOWSKI, MILLARD, 2000, p. 164). Para Beaulieu (2018, pp. 122 - 123), essa suposta rota de entrada faz sentido por três motivos principais: 1 - a região do norte de Diyala foi, posteriormente, chamada pelos gregos de Kossaios (uma palavra derivada do acadiano kasshu); 2 - um dos primeiros reis cassitas (Agum-kakrime) se atribuiu os títulos de "rei de Padan e Alman" e "rei de Gutium", regiões localizadas no Zagros; e 3 - os primeiros registros sobre os cassitas são de Sippar, na região norte da Babilônia, sendo um caminho lógico a ser feito (ver mapa). 


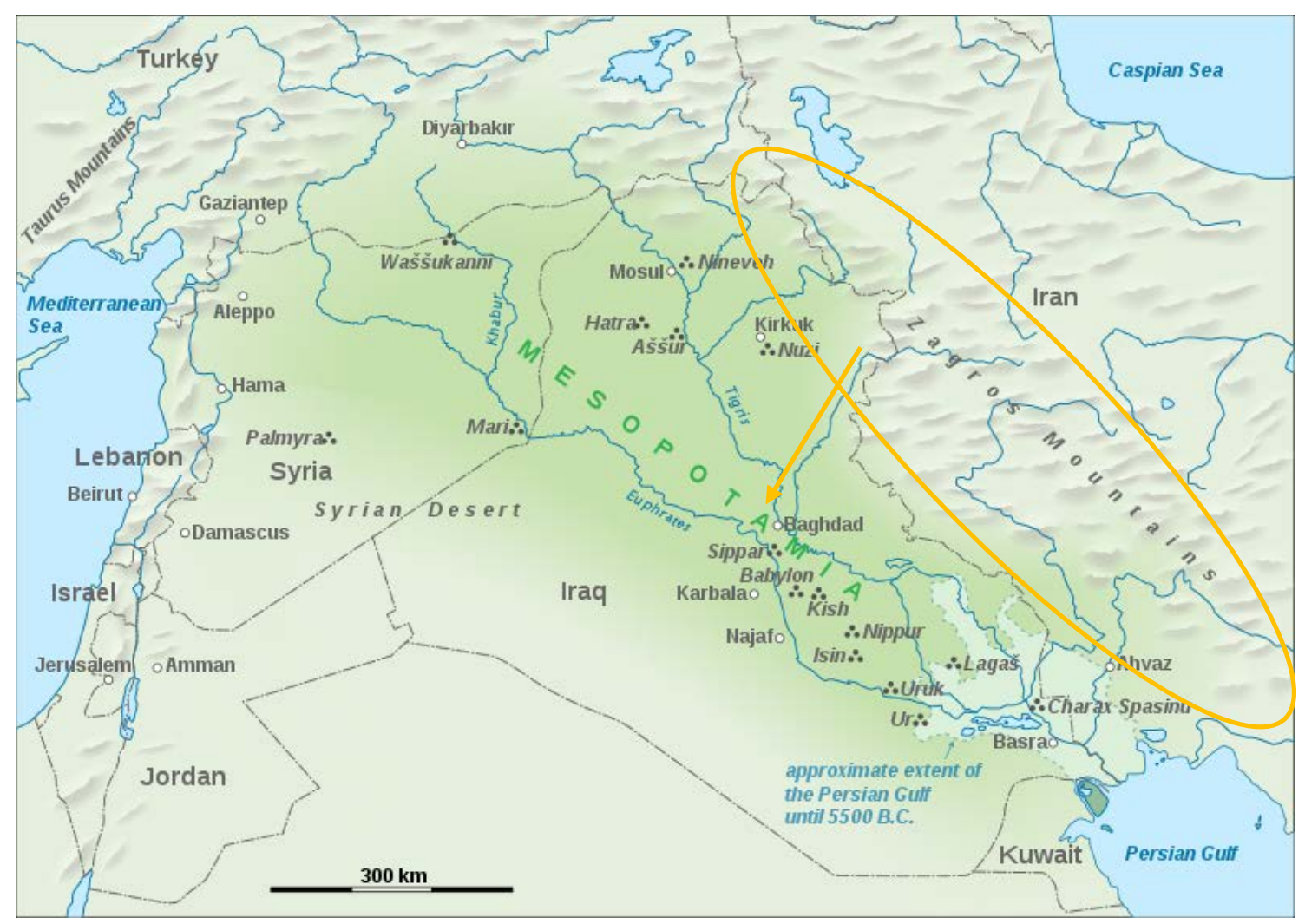

Figura 1: Mapa da Mesopotâmia

Fonte: TEK-EN, 2014, s/p. Destaques da autora.

O documento babilônico mais antigo, do qual temos registro, que aborda a presença de cassitas na região data ainda do reinado de Samsuiluma I, o filho de Hammurabi. Segundo ele, em cerca de 1742 AEC, o rei babilônico havia os enfrentado em Kikala (uma cidade provavelmente perto de Kish). A partir do último ano do governo de Samsuiluma I, as referências são cada vez mais frequentes e os escribas costumavam se referir aos cassitas coletivamente por meio de um termo com forte conotação militar: o logograma ERÍN (tropas). Isso ajuda a enfatizar a ideia de que o grupo era invasor e que os cassitas atuavam como mercenários, além do seu envolvimento com a cavalaria (BEAULIEU, 2018, p. 101).

Apesar dos cassitas terem, de fato, agido como mercenários e terem bons conhecimentos sobre cavalos, eles também participaram de outras ocupações em 
NEARCD: Revista Eletrônica de Antiguidade 2020, Volume XII, Número II - ISSN IS82-8713

Núclea de Estudas da Antiguidade - NEA

Universidade do Estado do Rio de Janeiro

ISSN 1982-8713

trabalhos sazonais. Aparentemente, muito de sua estrutura tribal foi mantida, com eles vivendo fora dos grandes centros urbanos em assentamentos. Estes funcionavam como "Casas", no sentido de estruturação hierárquica, na qual o líder do clã funcionava como um chefe de família - assim, cada "Casa" era a extensão de unidades familiares sob uma autoridade.

Aqueles que viviam nas áreas urbanas, por sua vez, parecem ter se assimilado na cultura acadiana bem rapidamente. Evidência disso é a adoção de nomes acadianos entre os cassitas, sendo que o contrário não acontece com a mesma intensidade (BEAULIEU, 2018, p. 125). Até mesmo os reis cassitas, após a conquista da Babilônia, passaram a optar por nomes acadianos. Na verdade, documentos sobre a sua cultura original são bastante raros, tamanha foi a aderência do grupo nos modos locais.

A própria língua cassita é pouco conhecida, uma vez que eles haviam optado por usar os idiomas locais para escrever os documentos no período em que eles governavam a Babilônia. O sumério continuou sendo a língua dominante em inscrições votivas e construções até o governo de Burraburiash II e, a partir de seu sucessor (Kurigalzu II), o acadiano se tornou cada vez mais frequente (BEAULIEU, 2018, p. 144). Nos dias atuais, o idioma cassita é conhecido exclusivamente por nomes próprios ou empréstimos linguísticos para o acadiano ${ }^{225}$, sendo que a maioria das palavras cassitas que foram adotadas pelo acadiano referem-se à cavalaria ${ }^{226}$. Como consequência dessa falta de documentação, até hoje não foi possível relacionar o cassita com nenhuma outra língua conhecida de modo convincente, apesar de alguns estudos terem procurado pelas semelhanças com o elamita, com o hurrita, com o luvita e com o hindi (GARELLI, 1969, pp. 135-136).

\footnotetext{
${ }^{225}$ Existem dois vocabulários cassita-acadiano, com verbos, substantivos e adjetivos.

${ }^{226}$ A associação entre cassitas e cavalos acontece desde o Período Paleobabilônico, o que sugere o papel importante dos cassitas no desenvolvimento das técnicas de cavalaria. Na época cassita, os cavalos babilônicos estavam entre os mais valiosos.
} 
ISSN 1982-8713

É interessante notar que apesar de haver a incorporação da língua acadiana durante o regime cassita, a cultura literária babilônica se desenvolveu de um modo bastante particular. As narrativas tradicionais, Paleobabilônicas continuaram existindo, mas foram padronizadas, criando o que Liverani (2009, pp. 506 - 507) chama de um período dos mestres autores e compiladores em detrimento de um período criativo, porém fluído e anônimo. Neste último, havia uma série de diferentes versões das histórias, que permanecem no anonimato e são de difícil catalogação. Naquele, os escribas se preocupavam em repetir, sem alterações, as obras do passado e focavam-se mais na canonização do que na criação. Por isso, séculos depois, os nomes dos escribas cassitas se mantiveram preservados e se tornaram famosos (LIVERANI, 2009, p. 506).

No que se refere a escrita em si houve uma evolução. É no período cassita, por exemplo, que se desenvolve a língua médio-babilônica/acadiana e a babilônica padrão. A primeira é uma transformação natural da linguagem, que foi usada em textos práticos como cartas e atos jurídicos ou administrativos. A escrita padrão, por sua vez, foi usada em textos literários e se caracterizava por ser uma mistura do antigo-babilônico com o médio-babilônico e outros elementos hiperarcaidos (LIVERANI, 2009, p. 506). O médiobabilônico acabou se tornando a língua franca do Período do Bronze Tardio e foi usado para estabelecer a comunicação diplomática entre os governantes do Antigo Oriente Próximo. Havia, evidentemente, alguns regionalismos, mas as cartas diplomáticas garantem uma vasta documentação em língua acadiana (médio-babilônica) espalhadas para além da Mesopotâmia.

Assim como a linguagem, o panteão cassita não foi adotado na Babilônia, apesar dos nomes de algumas divindades serem conhecidos - especialmente por comporem nomes de indivíduos cassitas (VAN DE MIEROOP, 2007, p. 173). Não há, portanto, nenhuma evidência de imposição da religiosidade, seja por adoção de rituais ou deuses, nos templos babilônicos. As únicas duas exceções são o deus Shuqmuma e sua consorte Shumaliya, que provavelmente têm suas origens no Zagros, mas foram adotados como 
ISSN 1982-8713

deuses dinásticos. A deusa Shumaliya é descrita como "senhora das montanhas brilhantes, que mora nos cumes e anda pelos caminhos nevados" (BEAULIEU, 2018, p. 123), em uma possível referência ao Zagros. Por outro lado, os cassitas tinham um apresso muito grande pelo deus sumério Enlil. Isso acontece, talvez, por servir como forma de legitimar seu poder no sul, já que Enlil era o deus mais importante de Nippur (tida como capital religiosa do Império Paleobabilônico); ou, talvez, por estabelecer uma conexão com o Zagros, uma vez que o templo de Enlil em Nippur era chamado de "Casa (que é a) Montanha", e entre seus epítetos estão "Grande Montanha" e "Senhor das terras estrangeiras" (BEAULIEU, 2018, p. 139).

Apesar da valoração de deuses babilônicos há um certo contraste entre quais divindades eram adoradas. O Período Paleobabilônico esteve muito ligado ao deus Shamash (da justiça) e Adad (heroico e guerreiro). Na época cassita, entretanto, existia uma grande popularidade de deuses relacionados à cura dos males morais ou físicos: destacando-se Marduk, Nabu e Gula (LIVERANI, 2009, p. 511). É possível que isso seja uma resposta aos momentos incertos anteriores, nos quais a Mesopotâmia passou por uma forte crise e fragmentação, tirando a centralidade babilônica das relações. Independentemente do caso, é importante ressaltar a assimilação cassita da cultura babilônica. Podemos não saber suas motivações, mas sabemos que a Babilônia continuou mantendo seus elementos fundamentais e permaneceu estável pelos próximos séculos.

\section{Babilônia Cassita (c. 1595 - 1155 aec)}

Cinco gerações sucederam Hammurabi antes do fim do Período Paleobabilônico, mas o declínio era cada vez mais evidente. Segundo Podany (2010, pp. 119 - 120), quase todas as cidades do sul parecem ter sido abandonadas entre c. 1738 e 1720 AEC, apesar de não serem completamente despovoadas. Sob o governo de Samsuditana, tataraneto de Hammurabi, a Babilônia se resumia aos espaços entre a 
capital no Eufrates e Mari e Terqa ao norte. Samsuditana (c. 1625 - 1595 AEC) não foi um rei preocupado com a expansão da Babilônia e procurou focar-se nas questões internas, mas fatalmente perdeu o controle de seu reino. Ele teve que controlar invasões elamitas, cassitas, mitânias e tropas de uma série de outros povos, contudo, foram os hititas que deram o golpe final, em c. 1595 AEC.

$\mathrm{Na}$ documentação babilônica o evento foi mencionado apenas brevemente na Crônica 40 ( $A B C 20$ - Crônica dos Reis Antigos) 227 , na qual afirma-se que "nos tempos de Samsuditana, os hititas marcharam na Acádia" (LIVIUS, 2020, tradução da autora). Os hititas, por sua vez, descreveram sua vitória, tendo marchado inicialmente para Aleppo e Terqa. A campanha hoje é conhecida pelo Edito de Telipinu, um rei hitita posterior ao período. Segundo o texto, os hititas, sob comando de Mursili, conquistaram Hana, ao norte e então invadiram a Babilônia. Destarte, eles não ocuparam a cidade, contentando-se a saquear e levar os espólios para a Anatólia.

Não sabemos como foi a batalha, mas se acreditarmos no Edito de Telipinu, os hurritas ajudaram os babilônicos a se defender: talvez de forma mais direta, na própria Babilônia, ou de modo indireto, criando uma resistência na Síria. Hurritas e hititas já haviam estabelecido uma inimizade quase impossível de ser revertida. Durante o próximo século, esses grupos continuaram entrando em conflitos (mesmo no período diplomático), que só foram superados após o fim definitivo de Mitani, decorrente do assassinato de Tushratta em um complô entre hititas e assírios. O importante aqui, contudo, é que após o ataque hitita, a Babilônia ficou sem rei - Samsuditana simplesmente desapareceu dos registros; talvez, estivesse morto ou, talvez, exilado (PODANY, 2010, pp. 123 - 124). Pior que isso, entre os espólios e os cativos, foram

\footnotetext{
${ }^{227}$ Existe uma tradução para o inglês disponível, ainda que fragmentada, no site: https://www.livius.org/sources/content/mesopotamian-chronicles-content/abc-20-chronicle-of-earlykings/
} 
NEARCD: Revista Eletrônica de Antiguidade 2020, Volume XII, Número II - ISSN IS82-8713

Núclea de Estudas da Antiguidade - NEA

Universidade do Estado do Rio de Janeiro

ISSN 1982-8713

levadas duas estátuas dos deuses Marduk e sua consorte Sarpanitum, as duas divindades protetoras da cidade.

Assim, a Babilônia ficou sem rei e sem seus deuses. Pode parecer exagero, mas naquele contexto, a estátua do deus era mais do que uma imagem, ela era o próprio deus. Por isso, as pessoas podem ter ficado bastante chocadas. A cidade ficou sem sua essência, sem seus deuses e desprotegida. O choque vinha, também, porque, apesar de existirem conflitos com frequência, a Babilônia era a representação da força, era próspera e possivelmente tida como "indestrutível" - e isso se provou errado. A Babilônia foi destruída por inimigos que, até então, não eram conhecidos; aos olhos de um babilônico, os hititas haviam chegado dos confins do mundo e desbancaram a principal cidade que já havia existido. De repente, em c. 1595 AEC, a Mesopotâmia estava sem uma unidade central, as cidades estavam destruídas e a política estava fragmentada. É um período obscuro, que, como mencionei acima, foi apelidado de Idade das Trevas: em parte pelo caos, mas também pela falta de vestígios.

Quando a poeira baixou encontramos uma dinastia cassita governando a Babilônia. Não sabemos como aconteceu essa tomada de poder, não há registros de nenhum evento específico. Provavelmente, os cassitas não tenham sequer tido uma participação ativa na queda de Samsuditana, mas apenas se beneficiado do vácuo de poder deixado pelos hititas na Mesopotâmia ${ }^{228}$. Sem documentações do período, é difícil traçar uma cronologia dos reis cassitas - para isso, as pesquisas se voltam para algumas listas reais (BEALIEU, 2018, p. 127). O primeiro dos reis parece ter sido Gandash, sobre o qual conhecemos apenas o nome. Ele foi seguido por Agum I, seu filho, depois referenciado como "Agum, o Grande", por Agum-Kakrime. As listas seguem com alguns outros nomes, ainda mais evasivos. Não há nenhuma evidência de que os primeiros reis

\footnotetext{
${ }^{228}$ Da mesma forma, o hurritas se estabeleceram no norte da Síria, com o Reino de Mitani e, mais ou menos nessa mesma época, o Egito expulsava os hicsos de suas terras e iniciava uma expansão pela sírio-palestina.
} 
NEARCD: Revista Eletrônica de Antiguidade 2020, Volume XII, Número II - ISSN IS882-8713

Núcleo de Estudas da Antiguidade - NEA

Universidade do Estado do Rio de Janeiro

ISSN 1982-8713

cassitas tivessem, de fato, governado a Babilônia, apesar de posteriormente assumir-se que o fizeram. O primeiro rei cassita que conhecemos por documentos contemporâneos ao seu governo é Karaindash, já em c. 1415 AEC. Na tabela abaixo podemos ver a sucessão cronológica da dinastia cassita:

Nome Data em AEC Eventos de destaque

\begin{tabular}{|c|c|c|}
\hline Gandash & ? & \\
\hline Agum I & $?$ & \\
\hline Kashtiliashu I & ? & \\
\hline$(\ldots)$. & $\ldots$ & \\
\hline Abirattash & $?$ & \\
\hline Kashtiliashu II & $?$ & \\
\hline Urzigurumash & ? & \\
\hline Agum II, kakrime & $?$ & \\
\hline Hurbazum (?) & $?$ & \\
\hline Shipta-Ulzi (?) & $?$ & \\
\hline (....) & ... & \\
\hline Burna-Buriash I & $?$ & \\
\hline Ulam-Buriash (?) & c. 1475 & $\begin{array}{l}\text { Conquista do País do Mar } \\
\text { (Ea-gamil) }\end{array}$ \\
\hline Kashtiliashu III (?) & $?$ & \\
\hline Agum III (?) & ? & $\begin{array}{l}\text { Destruição de Dur-Enlil no } \\
\text { País do Mar }\end{array}$ \\
\hline Karaindash & c. 1415 & $\begin{array}{l}\text { Primeiro vestígio cassita } \\
\text { contempotâneo }\end{array}$ \\
\hline Kadashman-Harbe I & c. 1400 & \\
\hline Kurigalzu I & $?$ & $\begin{array}{l}\text { Fundação de Dur-Kurigalzu } \\
\text { e aparecimento dos } \\
\text { primeiros kudurrus }\end{array}$ \\
\hline
\end{tabular}


NEARCD: Revista Eletrônica de Antiguidade 2020, Volume XII, Número II - ISSN IS882-8713

Núcleo de Estudas da Antiguidade - NEA

Universidade do Estado do Rio de Janeiro

ISSN 1982-8713

\begin{tabular}{|c|c|c|}
\hline Kadashman-Enlil I & c. $1374 ?-1360$ & Cartas de Amarna \\
\hline Burna-Buriash II & c. $1359-1333$ & $\begin{array}{l}\text { Cartas de Amarna e início } \\
\text { dos arquivos de Nippur }\end{array}$ \\
\hline Karahardash & c. 1333 & \\
\hline Nazi-Bugash & c. 1333 & $\begin{array}{l}\text { Intervenção assíria de } \\
\text { Ashur-uballit I }\end{array}$ \\
\hline Kurigalzu II & c. $1332-1308$ & \\
\hline Nazi-Maruttash & c. $1307-1282$ & \\
\hline Kadashman-Turgu & c. $1281-1264$ & \\
\hline Kadashman-Enlil II & c. $1263-1255$ & \\
\hline Kudur-Enlil & c. $1254-1246$ & \\
\hline Shagarakti-Shuriash & c. $1245-1233$ & \\
\hline Kashtiliashu IV & c. $1232-1225$ & $\begin{array}{l}\text { Intervenção assíria de } \\
\text { Tukulti-Ninurta I e fim dos } \\
\text { arquivos de Nippur }\end{array}$ \\
\hline Enlil-nadin-shumi & c. 1224 & Início da ocupação assíria \\
\hline Kadashman-Harbe II & c. 1233 & \\
\hline Adad-shuma-iddina & c. $1222-1217$ & \\
\hline Adad-shuma-usur & c. $1216-1187$ & Fim da ocupação assíria \\
\hline Meli-Shipak & c. $1186-1172$ & \\
\hline Marduk-apla-iddina I & c. $1171-1159$ & \\
\hline Zababa-shuma-iddina & c. 1158 & \\
\hline Enlil-nadin-ahi & c. $1157-1155$ & \\
\hline
\end{tabular}

Aparentemente, a unificação da Babilônia, agora liderada pelos cassitas, aconteceu de forma gradual, com três eventos principais: 1) Ea-gamil (rei do País do 
NEARCD: Revista Eletrônica de Antiguidade 2020, Volume XII, Número II - ISSN IS82-8713

Núclea de Estudas da Antiguidade - NEA

Universidade do Estado do Rio de Janeiro

ISSN 1982-8713

$\operatorname{Mar}^{229}$ ) fugiu de uma rebelião interna em seu território e se exilou em Elam (c. 1475 AEC); 2) Ulam-Buriash (cassita) marchou para o País do Mar e reclamou o trono; 3) Agum III (cassita) pôs fim à dinastia do País do Mar, após destruir a fortaleza de Dur-Enlil (próxima a Nippur). Depois da tomada do País do Mar, unidade babilônica se tornou irreversível e "apesar da Babilônia ainda experenciar períodos de fraqueza política, fragmentação regional e ocupação estrangeira, nunca novamente o país iria se dividir entre dinastias rivais" (BEAULIEU, 2018, p. 132).

Vinte e quatro anos depois da captura dos deuses Marduk e sua consorte Sarpanitum, o rei cassita Agum-kakrime conseguiu recuperar as estátuas por meio de um acordo diplomático em c. 1504 AEC (PODANY, 2010, pp. 127 - 131). É possível que isso tenha acontecido como uma forma de legitimar seu poder, sendo conhecido como o rei responsável por trazer os deuses de novo para a cidade; talvez, fosse uma causa que ele realmente acreditasse e, nesse caso, a Babilônia precisava dos deuses para ficar segura. É interessante notar, porém, que nos registros de Agum-kakrime afirma-se que os deuses não haviam sido raptados, mas estavam em terras estrangeiras porque queriam estabelecer relações com os reis de Hatti e Hana.

O ataque hitita na Babilônia de c. 1595 AEC resultou em um conhecimento mútuo de dois reinos que se consideravam centrais. Assim como os babilônicos se imaginavam no centro do mundo, os hititas se depararam com uma riqueza e conhecimento que não eram imaginados fora da Anatólia - para eles a Mesopotâmia era os confins do mundo. Consequentemente, isso desencadeou um interesse econômico em ambas as partes, em busca de produtos exóticos e, para isso, a diplomacia começou a ser pensada em uma escala maior. No governo de Kardaindash,

229 O País do Mar, localizado no sul mesopotâmico, havia se rebelado contra a Babilônia e se desvencilhado do controle dos herdeiros de Hammurabi, estavam envolvidos nos anos finais do Período Paleobabilônico e sofreram com as crises da Idade das Trevas. O País do Mar durou entre c. 1725-1475 AEC (BEAULIEU, 2018, p. 129) 
por exemplo, aconteceram negociações com o rei assírio Ashur-bel-nesheshu, registradas na História Sincrônica (PRITCHARD, 1969, pp. 272 - 274).

Karaindash foi o rei responsável pela dispersão da palavra Karduniash. Originalmente, o termo se referia aos territórios cassitas no norte, mas, com o tempo, tornou-se um sinônimo para o reino da Babilônia. O título de "Rei de Karduniash" foi amplamente utilizado nas cartas diplomáticas do século XIV AEC e pode ser atestado nas Cartas de Amarna ${ }^{230}$. Nos documentos assírios, o termo continuou sendo usado como conceito territorial para se referir à Assíria até o século VII AEC (BEAULIEU, 2018, p. 135).

Além das relações diplomáticas mais abrangentes, outra tendência que podemos notar nessa época é com o neto de Karaindash, o rei Kurigalzu I. Ele mandou construir a cidade Dur-Kurigalzu, cerca de $100 \mathrm{~km}$ ao norte da Babilônia, onde foi estabelecida a nova residência real cassita (BEAULIEU, 2018, p. 137). Dur-Kurigalzu é a primeira entre as novas capitais criadas durante o Período do Bronze Tardio, mas não é a única. Há o caso famoso de Akhetaton no Egito e outros menos popularmente conhecidos: no Elam (quando criou-se Dur-Untash em substituição de Susa) e na Assíria (com a construção de Kar-Tukulti-Ninurta poucos quilômetros ao norte de Ashur). Infelizmente, não sabemos dizer qual é (e se tem) a relação dessas mudanças - talvez fosse uma forma de se reformular acompanhando as demais transformações pelas quais o Oriente Próximo passava, mas isso nada mais é do que uma suposição.

Em Dur-Kurigalzu estabeleceu-se o culto aos deuses Enlil, sua consorte Ninlil e seu filho Ninurta. Como mencionado acima, os cassitas parecem ter tido alguma ligação com esse deus e o tornaram regente da dinastia. Provavelmente, cartas diplomáticas como as de Amarna e as de Boğazköy fossem guardadas em Dur-Kurigalzu: lá encontrouse um fragmento com termos referentes ao sistema diplomático da época com o nome

\footnotetext{
${ }^{230}$ São um conjunto de cartas, encontradas no Egito, que refletem a diplomacia no século XIV AEC.
} 
NEARCD: Revista Eletrônica de Antiguidade 2020, Volume XII, Número II - ISSN IS82-8713

Núclea de Estudas da Antiguidade - NEA

Universidade do Estado do Rio de Janeiro

ISSN 1982-8713

de Kadashman-Enlil (não sabemos de o I ou o $\|^{231}$ ). Entretanto, a cidade foi destruída pelos elamitas séculos depois e não restou material suficiente para se averiguar.

O período entre c. 1400 e 1300 AEC é conhecido como Era de Amarna, quando falamos em termos de relações exteriores. O termo é referente ao conjunto de cartas diplomáticas encontradas em Amarna, no Egito, mas é um tanto ingrato, uma vez que o sistema já existia e continuou existindo depois do período que as Cartas de Amarna cobrem. Graças à essas correspondências, porém, fica possível entender um pouco sobre como era o contato e os interesses dos reis babilônicos para além das suas fronteiras. Entre os assuntos mais frequentes estão o estabelecimento de casamentos e a troca de materiais: a Babilônia enviava cavalos, bigas e lápis-lazúli para o Egito e, em troca, recebia ouro e móveis luxuosos ${ }^{232}$. Uma carta em especial (EA9) aponta o descontentamento dos babilônicos com a ascensão assíria no radar internacional.

É verdade que, no século XVI AEC, os reis Burraburiash I e Puzur-Ashur II haviam estabelecido um tratado de paz, em busca da aliança contra um inimigo comum na fronteira síria (PODANY, 2010, p. 129). Esse inimigo era o Reino de Mitani que se expandia rapidamente. A Assíria, por muito tempo, esteve presente e ativa no norte mesopotâmico, mas não possuía uma grande representatividade externa, tendo caído sob o controle de Mitani. A Babilônia, por sua vez, se manteve como uma grande potência.

No final do século XV AEC, a Assíria começou a ganhar sua independência e durante o governo de Ashur-uballit I (c. 1363 - 1328 AEC) já estava confiante o suficiente para emergir como uma potência. O receio em relação a isso, apontado por Burraburiash II na carta EA9, se mostra pertinente. Burraburiash II casou-se com uma filha de Ashuruballit I e, com ela teve um filho chamado Karahardash, que o sucedeu no trono.

\footnotetext{
${ }^{231}$ Cartas datadas de governos entre os dois Kardashman-Elil mencionam a existência de relações com Kardashman-Enlil I.
}

${ }^{232}$ A tradução, em inglês, dessas cartas pode ser vista em Rainey (2015) e Moran (1992) 
ISSN 1982-8713

Durante o regime de Karhardash, contudo, houve uma revolta interna, que foi reprimida por Ashur-uballit I. O rei assírio matou o usurpador e nomeou, seu neto, Kurigalzu II para o trono, irmão de Karhardash (BEAULIEU, 2018, p. 143). Apesar de ser Kurigalzu II ser o herdeiro legítimo, a intervenção de Ashur-uballit I garantia que a Assíria ainda tivesse alguma ligação oficial com a monarquia da Babilônia.

O período que compreende entre os governos de Kurigalzu II e Kashtiliash IV é muito bem documentado em termos textuais, mas pouco sabemos sobre a situação política. Algumas crônicas ${ }^{233}$ narram embates com a Assíria, mas as versões trazem são bastante conflitantes. Segundo Beaulieu (2018, pp. 143 - 148), existem documentos hititas que indicam uma aliança entre Hatti e Babilônia para se fortificarem militarmente. Depois da queda de Mitani, a Assíria conseguiu estabelecer certo domínio ao norte e, eventualmente, atacou também, a Babilônia. Segundo o Épico de Tukulti-Ninurta (rei assírio que governou entre c. 1243 e 1207 AEC), a campanha contra Kashtiliash IV aconteceu porque o rei Babilônico havia quebrado um juramento feito ao deus Shamash e, assim, o deus Enlil mandou Tukulti-Ninurta para vingá-lo. O rei Kashtiliash IV foi levado como prisioneiro e a Assíria reivindicou ao trono. Acredita-se que os três sucessores de Kashtiliash IV, citados na Lista Real A (PRITCHARD, 1969, p. 172), eram marionetes do governo assírio, apesar de serem filhos do antigo rei babilônico. O grau dessa intervenção, porém, é difícil ser compreendido em sua totalidade pela fragmentação e ambiguidade das fontes.

Certamente, a Assíria tinha um interesse crescente na Babilônia e isso fica bastante visível no fim do período cassita. A queda foi súbita e o confronto veio de duas frontes: de um lado atacaram os assírios, de outro, os elamitas. A aparente paz e estabilidade que existia no governo de Meli-Shipak logo deu lugar aos ataques do rei assírio Ashurdan I (c. 1178 - 1133 AEC). Segundo a História Sincrônica (PRITCHARD, 1969, pp. 272 - 274), Ashurdan I promoveu uma campanha contra o rei cassita

\footnotetext{
${ }^{233}$ Crônica 45 e História Sincrônica.
} 
Zababa-shuna-iddina em c. 1158 AEC e o rei elamita Shutruk-Nakhunte alegou que, por ser casado com a filha de Meli-Shipak, ele era o herdeiro do trono babilônico. Assim, Elam marchou para as cidades leste e norte da Babilônia (Eshnunna, Sippar, Acádia e Dur-Kurigalzu), as conquistando e saqueando - foi o fim definitivo no governo de Zababa-shuna-iddina (LIVERANI, 2009, p. 499). Os cassitas ainda resistiram por três anos no sul, sob a liderança de Enlil-nadin-ahi, mas ele acabou sendo derrotado por Kutur-Nakhunte (filho de Shutruk-Nakhunte) e levado para o Elam, em c. 1155 AEC. Os cassitas nunca mais recuperaram o controle da região, encerrando, pela última e definitiva vez, o governo cassita da Babilônia.

\section{Reflexões finais}

Não há muita documentação disponível que nos ajude a entender a história política da Babilônia Cassita ou as características particulares da cultura cassita de modo satisfatório. Ainda assim, é possível perceber alguns elementos específicos desse período. Sob uma dinastia cassita, a região testemunhou o florescimento da literatura babilônica, com uma valorização dos textos sumérios e acadianos. Muitos dos trabalhos literários mais significantes da Mesopotâmia são conhecidos por cópias feitas nessa época, como o Épico de Gilgamesh (a composição literária mais longa da Mesopotâmia) e o Hino a Marduk de Ludlul bēl nēmeqi.

A cultura literária babilônica parece ter se desenvolvido organicamente, com pouca influência dos cassitas. A língua cassita, como mencionei anteriormente, não foi utilizada em documentos oficiais e o que conhecemos sobre ela restringe-se aos nomes próprios ou de alguns deuses e os empréstimos linguísticos para o acadiano. $O$ fato de os termos adotados serem relacionados à cavalaria ajuda a confirmar a relação e os conhecimentos dos cassitas sobre técnicas e cuidados de cavalos - concordando com a valorização dos cavalos babilônicos no exterior. Assim, sabemos que pelo menos nesse sentido houve alguma colaboração cassita na Babilônia. Outro elemento trazido são os 
kurrudus (espécie de estelas de doação de terras). Destarte, além disso, os cassitas parecem terem tido pouco impacto na cultura local.

Em termos políticos, os títulos utilizados pelos reis se mantiveram os mesmos já usados no Período Paleobabilônico, com poucas exceções. As formas de governo e cultos religiosos, igualmente, não sofreram muitas mudanças. Um ponto de diferença, porém, é que durante o Período Paleobabilônico a população era majoritariamente urbana, mas, com a crise do III Milênio AEC, a situação econômica mudou e o reino passou a contrastar poucos centros urbanos e grandes áreas de cultivo e pequenas comunidades rurais no interior. Assim, na Babilônia Cassita, existiam três cidades principais, que se mantiveram muito por uma questão de status: Babilônia, DurKurigalzu e Nippur. O que podemos dizer é que durante dos três séculos em que estiveram no poder, os cassitas conseguiram manter a estabilidade e uma unidade bastante representativa.

\section{Referências}

\section{Documentação:}

LIVIUS. ABC 20 (Chronicle of Early Kings), 2020. Disponível em: https://www.livius.org/sources/content/mesopotamian-chronicles-content/abc-20-chronicleof-early-kings/. Acesso em 14 de julho de 2020.

MORAN, William. The Amarna Letters. Baltimore: The John Hopkins University Press, 1992. PRITCHARD, James B. Ancient Near Eastern Texts. Related to the Old testament. Princeton: Princeton University Press, 1969.

RAINEY, Anson F. The el-Amarna Correspondence. Leiden: Brill, 2 vol., 2015.

\section{Referências bibliográficas:}

BEAULIEU, Paul-Alan. A History of Babylon, 2200 BC-AD 75. Chichester: Wiley Blackwell, 2018.

BIENTOWSKI, Piotr; MILLARD, Alan. Dictionary of the Ancient Near East. Londres: The British Museum Press, 2000. 
NEARCD: Revista Eletrônica de Antiguidade 2020, Volume XII, Número II - ISSN IS882-8713

Núcleo de Estudas da Antiguidade - NEA

Universidade do Estado do Rio de Janeiro

ISSN 1982-8713

COHEN, Raymond; WESTBROOK, Raymond (eds.). Amarna Diplomacy. The beginnings of international relations. Baltimore: The Johns Hopkins University Press, 2002.

GARELLI, Paul. O Oriente Próximo Asiático: das origens às invasões dos povos do mar. São Paulo: Pioneira/EDUSP, 1969.

LIVERANI, Mario. Antigo Oriente. História, Sociedade e Economia. São Paulo: EDUSP, 2009.

PODANY, Amanda H. Brotherhood of Kings. How international relations shaped the Ancient Near East. Nova York: Oxford University Press, 2010.

TEK-EN, Goran. Map of Mesopotamia. Wikimedia Commons, 2014. Disponível em: https://commons. wikimedia.org/w/index.php?curid=30851043. Acesso em 30 de junho de 2020.

VAN DE MIEROOP, Marc. A History of Ancient Near East ca. 3000 - 323 BC. Oxford: Blackwell Publishing, 2007. 